\title{
Makers and Models: Two Approaches to Truth, and their Merger
}

\author{
Peter Simons \\ Trinity College Dublin \\ Published in: Miroslaw Szatkowski, ed., God, Truth, and other Enigmas. \\ Berlin: de Gruyter, 2015, 153-168.
}

\begin{abstract}
A semantic account of truth along the lines initiated by Alfred Tarski has a number of advantages that render it theoretically attractive. One is that it becomes possible to use the same methods and materials to define both truth and logical consequence. On the other hand the theory comes at a price. One element is that the ontological cost of deploying the tools required to define truth render it unacceptable to those of a non-platonist persuasion, something of which Tarski was only too painfully aware. Another element is that it is not clear how the Tarskian method of delimiting the true from the false connects with the intuitive notion of truth as answering in some way to the way things are in the world. It was for this reason among others that the modern theory of truth-making was initiated. Truthmaking, whatever form the correct theory may take, for its part eschews the idea that truthmakers should be in general epistemically and semantically transparent to the user of the idiom whose truth-bearers are thereby rendered true. There thus appears to be a radical disconnect between the model-theoretic approach to truth and the truth-making account, so that they might as well be about different things. This paper will attempt to bring the two approaches together, show how they interact and complement one another, and can be deployed together to provide a nominalistically acceptable account of truth and consequence.
\end{abstract}

\section{Introduction: Tarski and Nominalism}

The aim of this paper is to bring together currently divergent approaches to aspects of the theory of truth in the service of furnishing a nominalistically acceptable way to approach truth in both empirical and mathematical contexts. Like much of the work on which I have spoken in Warsaw, is in effect a footnote to Tarski. In particular it picks up a couple of lacunae left by his work, awesomely comprehensive though that is. The first concerns the input to the lowest level of a recursive account of truth, concerning how atomic propositions get to be true, for which purpose some years ago we ${ }^{1}$ introduced the notion of truth-maker. The second concerns the intellectual schizophrenia suffered by Tarski: a nominalist in his philosophical heart but a platonist at mathematical work by methodological compulsion, a "tortured nominalist", as he described himself. ${ }^{2}$ Probably the average philosopher's reaction to Tarski's unresolved dilemma is to shrug, think "So much the worse for nominalism", and

1 The 'we' is a genuine plural. See Mulligan, Simons and Smith 1984.

2 To Oswaldo Chateaubriand: see Feferman and Feferman 2008, 52. 
look for a biographical or psychological explanation as to why the great logician should have been nominalistically inclined. My reaction is the opposite: it is to consider how we can retain as much as possible of Tarski's results and insights within the constraints of a strict nominalism. ${ }^{3}$ It is instructive here to compare Tarski with his teacher Leśniewski. The latter's nominalism was so uncompromising that he was prepared to forego logical results, fame, friendships and editorial influence rather than be sullied with the platonism of set theory. As a result, Leśniewski's achievements in logic are greatly outrun by those of his ontologically less fastidious colleague. I shall be looking to radically extend ideas of Leśniewski in the interest of boosting the power of nominalism to give an account of mathematical truth.

The talk presupposes and does not argue for certain framework assumptions. One is obviously nominalism, by which I mean simply the denial that there are any abstract entities. This of course rules out mathematical objects as standardly conceived. This is part of a broader metaphysical framework assumption which I call naturalism, according to which all that exists is within the spatio-temporal-causal framework of the cosmos within which we are situated. This assumption rules out much more than abstract entities: in particular it rules out abstract attributes and states of affairs, Cartesian minds, disembodied souls, an eternal deity, and alternative possibilities. It does not rule out universals provided these are construed in a modest Aristotelian way as present where their instances are. Most of these denials are not operative in this paper.

Another contentious assumption driving much of what follows is a principle of sufficient reason, according to which there is always some kind of account that can be had when a proposition is true as to why it is true. The account is I believe not uniform in kind across all kinds of truths, but the question always makes sense, even if we don't know or have an answer to it.

My final prefatory note concerns two terminological decisions. I want a fairly neutral and readily understood term covering the variety of things - mental, linguistic and otherwise representational - that can be true or false. I shall co-opt the old term 'proposition' for this purpose. If I need to refer to a proposition in the sense of Church, which is that of Frege's Gedanke and Bolzano’s Satz an sich, I shall simply say 'abstract proposition'. In parallel, I really ought to replace the equally ugly term 'truth-maker' by something more mellifluous, such as 'fact', but in spite of all temptations, parental pride still prevails here for now.

3 I started this in Simons 2008 but now think we can go further. 
2 Truth, Consequence, and Models

Modern truth theory, the theory of logical consequence, and model theory have a common point of origin, namely Tarski. In the work Pojecie prawdy w jezzykach nauk dedukcynych, (The Concept of Truth in the Languages of the Deductive Sciences), published after delays in 1933 but first presented by Jan Łukasiewicz on 21 March 1931, Tarski laid the groundwork for much subsequent discussion of the concept of truth. Several facts about this work need recalling for what follows. The first is that Tarski deliberately limited the scope of his theory to formalized languages in precisely tidied-up logic and mathematics, because its application beyond these narrow confines was threatened by the semantic paradoxes. So despite the vernacular examples Tarski gives to illustrate his Convention T, the theory was never applied by him to the vernacular, although he later conceded that fragments of natural languages might be tractable by his methods. Secondly, despite the tenor of much subsequent philosophical discussion, the heart of Tarski's theory is not Convention T, which is a constraint intended to ensure that the theory conforms to our intuitive, Aristotelian conception of truth. Rather, it is the definition of truth and falsehood in terms of the broader concept of satisfaction of an open sentence by a sequence of objects. Thirdly, in order to define satisfaction and various other technical concepts within his theory, Tarski employs a relatively modest mathematical machinery consisting of some set theory, or equivalently, some higher types in a type theory, and he treats expressions of an infinite language as types rather than tokens. No doubt this lapse into the use of abstracta contributed to the disapproval voiced by Leśniewski towards Tarski's theory. Fourthly and finally, Tarski's theory makes no distinction between different kinds of truth, such as truth and necessary truth, or mathematical truth and non-mathematical truth. Where the notion of truth is unproblematically applicable, it is a single unified concept. That the true cannot always be delimited from the false by the methods of the paper is one of Tarski's results. His conjecture that one could give an axiomatic account for more powerful languages is one that Tarski never followed up, and has only recently begun to be investogated more thoroughly.

The concept of satisfaction is so defined and deployed that once truth and falsehood are given for atomic sentences, their application is extended to complex and quantified sentences by straightforward recursive clauses. This leaves to be considered the question how the atomic sentences get to be true or false: we come to this lacuna later. More positively, it enables Tarski to define the notions of interpretation and model so that in his paper of 1935/6 
'O pojęciu wynikania logicznego' ('Über den Begriff der logischen Folgerung') he is able to define the concept of logical consequence in the way now universally accepted, so that a sentence $c$ is a logical consequence of a set of sentences $P$ if and only if every model of the sentences $P$ (interpretation under which they all are true) is a model of $c$.

Although there are partial precedents for both of Tarski's achievements, in particular the semantic account of consequence is comprehensively anticipated by Bolzano's concept of logische Ableitbarkeit published in his Wissenschaftslehre of 1837, it was the precise account of truth and consequence in terms of satisfaction which put both concepts on a firm formal footing for the first time. Satisfaction employs the concept of a countably infinite sequence, or in later versions of the theory, finite sequences of arbitrary length. The concepts of finite and countably infinite sequence are mathematical ones whose representation to date has invariably employed a platonistic ontology, whether through set theory, function theory, or higher types.

These works of the 1930s formed the basis of the development of model theory by Tarski and his students in the 1940s and 1950s, which "West Coast" model theory was progressively integrated with the "East Coast" model theory of Abraham Robinson. It is interesting how far the theory of models has come from its origins. Ask a modern mathematician what model theory is and they will likely tell you that it is a method for classifying mathematical structures by means of axioms, ${ }^{4}$ which is in many ways a reversal of Tarski's approach. But no matter, mathematics can look after itself, and does. What I shall retain here is the much more elementary idea of a structure being a model of a proposition or propositions, as used in the definition of logical consequence. In this sense the intuitive notion predated Tarski and was in mathematical use in giving consistency and independence proofs since Riemann, Beltrami, Klein and Hilbert in 19th century geometry and also in use by Pieri, Padoa and Hilbert in discussions of definability - all issues that were dear to Tarski.

\section{Makers}

When Aristotelian and Tarskian ideas of truth are applied to vernacular languages, while the treatment of complex and quantified sentences follows that of the recursive truth-clauses we have learnt from Tarski, there is still the question of how the atomic sentences which start the recursive ball rolling get to be true or false. Tarski's Convention T provides a constraint.

4 This is what is stated in the authoritative textbook Hodges 1997. 
According to it, for example the Polish sentence 'Śnieg jest biały' is true if and only if snow is white. What conformity to this constraint amounts to is a matter of dispute. Minimalists about truth claim that all there is to truth is encapsulated in T-sentences, while others insist there is more to it than that. One who does so insist is Aristotle, who says that the proposition that you are pale is true not just if and only if you are pale, but because you are pale (and not vice versa). ${ }^{5}$ Likewise the Tractarian Wittgenstein, for whom an atomic sentence is true because its corresponding state of affairs exists (besteht), ${ }^{6}$ sees propositions' being true consisting in their conformity with the way things are. These are traditionally taken as correspondence theories. Whether Tarski's theory is a correspondence theory or not is a matter of contention that need not detain us. Suffice it that one widely accepted answer to the question as to what it is about the world in virtue of which an atomic sentence is true turns on an ontological rather than logical sufficient reason: the proposition is true because certain entities exist, and it is these entities that are called the truth-maker for the proposition in question.

In the context of nominalism any putative truth-makers will have to be particulars rather than abstract objects. In certain cases abstract entities would be prima facie candidates for truth-makers for the propositions in question, such as the existential propositions

There are four prime numbers between 10 and 20

There are infinitely many prime numbers

So truths like these which on the face of it appear to call for the existence of abstract entities will need an alternative explanation.

Contingently true atomic propositions about everyday and scientific matters stand in need of a worldly reason why they are true. In our original 1984 paper, the drive to a nominalistically acceptable account lay behind our highlighting tropes (there called 'moments') as plausible candidate truth-makers for a wide range of such propositions. That paper highlighted two further facets of our truth-making theory. Firstly, we did not expect all propositions, or even all contingent propositions, to have a truth-maker. We were from the start not (what is now called) truth-maker maximalists. The most patent examples of propositions that make trouble - we think terminal trouble - for maximalism are

5 "It is not because we truly think you are pale that you are pale, but it is because you are pale that we say so truly." Metaphysics, $1051 \mathrm{~b} 7$.

6 "4.21 The simplest kind of proposition, an elementary proposition, asserts the existence of a state of affairs. [...]

"4.25 If the elementary proposition is true, the state of affairs exists; if the elementary proposition is false, the state of affairs does not exist." (Tractatus LogicoPhilosophicus). 
(1) true negative existentials, such as

Batman does not exist

There are no flying horses

(2) true negations, such as

This sweater is not green

Putin does not admire Gorbachev

and

(3) mixed propositions, such as

This sweater is woollen or not green

The initial motivation for considering truth-making in the alternative Australian tradition ${ }^{7}$ was to ensure that contingent truth was not cut adrift from reality. Gilbert Ryle's account of truths about the mind in terms of dispositions to behave and the analysis of these in terms of counterfactual conditionals was found wanting precisely because there was nothing in reality that constrained the truth or falsity of such propositions: they dangled semantically. Despite the later avowal of maximalism by Armstrong, ${ }^{8}$ that motivation likewise did not require truthmaker maximalism, but only the weaker thesis, articulated by John Bigelow, that truth supervenes on being. ${ }^{9}$

Secondly, we noted that apart from some superficial cases and steps, the account of what the truth-makers are for most true propositions with truth-makers is largely indecipherable from semantic considerations alone. For instance it may be true that

Sarah has a headache but apart from instancing Sarah's subjective experience and postulating the existence of a dependent particular bodily state currently inherent in Sarah, that tells us nothing about what having a headache in general consists in, which is the job of physiology, not semantics, let alone the minute details of what this particular headache consists in. Call this the semantic opacity of truth-makers. For this reason truth-making cannot be reduced to representation plus grounding. The idea in that case would be that the fact represented by 'Sarah has a headache' is grounded in other facts, which would be the ultimate truth-makers for that truth. The physiological condition grounding Sarah's headache is not represented by 'Sarah's headache' or 'Sarah has a headache', or by any other actually thought proposition, and would only be represented by some proposition if propositions are abstract and represent facts or

7 Where the term 'truthmaker' (without a hyphen) was invented, independently and somewhat earlier than us, by C. B. Martin.

8 Armstrong 2004.

9 Bigelow 1988, 133. 
states of affairs independently of human activity. But both abstract propositions and states of affairs are beyond the nominalist pale, so the truth-makers for the actual proposition make it true without being represented by it, and most often without being represented by anything.

\section{Models}

The theory of truth-making was devised for contingent propositions and is not easily adapted to necessarily true or necessarily false propositions, even should one suppose it desirable to so apply it. Since necessary propositions have their truth-status come what may, it is generally otiose to look for something in the world forcing them to be what they will be anyway, although sometimes there will per accidens be truth-makers. For example, the same rain that makes it true that it rains in Warsaw on 17 September 2013 makes it also true by the entailment principle that it rains or does not rain in Warsaw on 17 September 2013. But this is a tautology and would have been true also had it not been raining then, so the rain in no sense forces the proposition to be true: and the proposition's truth places no constraints on the way the world is. In the case of truths of logic, an account of how they are true in all circumstances is plausibly required to appeal precisely to those recursive clauses devised to account for the truth of complex propositions in Tarski's theory, in each case relativized to an interpretation over a domain, and then quantified over. When we are considering alternative cases or possibilities, we typically do not have any entities that do any truth-making, so the additional layers of contingent ontological detail lying behind actual truth is lacking. That means that it is unpromising to look at relativizing the idea of truth-making to possible worlds as a way to account for necessity. On the other hand the much balder semantic ideas of terms having denotata, predicates having extensions, logical constants having fixed roles, and propositions being true or false, do not require the level of detail lying behind and attendant upon actual truth. These bald correlations are all that is required to generate models, which is why model theory can afford to be mathematical and not have to consider the empirical and circumstantial detail that real truth-making involves.

It thus looks as though the idea of truth-making evoked to service the account of truth simply fails to connect with that of a model evoked to account for logical truth and logical consequence, to the detriment of one or both aspects. There are three parts to a response to this worry. The first is that the notion of a model is schematic, so it is to be expected that arbitrary models lack the circumstantial and empirical detail of the actual case. The second is that because the notions of denotation, extension and truth-value do have application in the 
actual case, the detail comprehends the skeletal schema in that case, but not in the others. Indeed the presence of all the additional corroborative detail is part of what it is to be actual. The third is that we should not expect that an account of how truths are true in one area will automatically apply to truths in all areas. We have not mentioned this, but to the extent that the notions of truth and falsity are applicable in such axiological areas as ethics and aesthetics (which non-cognitivists would in any case dispute), we might well expect them to work in a very different way from the core cognitive areas.

In order to be in a position to represent a schema allowing alternative interpretations and models to be defined for propositions, we need objects to be denotations and extensions, and something like truth-values. The last are not crucial: provided we can mention at least one true proposition and one false one, all truths will be materially equivalent to the selected truth and all falsehoods to the selected falsehood. Denotation (at least for singular names) is easy: the object named is the denotatum. It is extensions of predicates that hitherto have called for abstracta, whether sets of tuples, sequences, functions or whatever. While I have indicated elsewhere ${ }^{10}$ that a nominalist can get by to an unexpected degree without gathering meaning together in unified packages called extensions, it would be nice to have substitutes for the standard items in order to apply the methods of standard semantics. To that task we turn.

\section{Multitudes}

The logician Leśniewski refused to be pushed by anyone into doing logic in a way which he could not square with his philosophical conscience. That included not being pushed by his logical hero Gottlob Frege into treating all names as singular denoting terms. In Leśniewski's logic names can be empty, failing to denote anything (as in later free logic, or in the vernacular according to Frege), and they can also be plural, denoting more than one thing (as in the Aristotelian tradition). To employ a term Leśniewski did not, and of which he probably would have disapproved, let us call the several things denoted by a plural term a multitude. Examples of multitudes are Whitehead and Russell, the people in this room now, the four evangelists, the Kings and Queens of Poland, and the Irish laureates of the Nobel Prize for Literature to 2012 (Yeats, Shaw, Beckett and Heaney).

Given a multitude, which is just these several individuals, and not a further individual over and above them (unlike the associated set), we may go on not only to distinguish

10 Simons 2008. 
different multitudes, but to demarcate and count groups of them. For example we may consider how many national groups of Literature Nobel Prize winners there are, which would include, alongside the Irish, groups from France, Germany, Poland, Russia, Britain, Austria, the United States, South Africa, India, and so on. Some of these groups have only one member, others have several. Consider the multitudes that are authors of multi-authored logic treatises published between 1900 and 2000. They would include Whitehead and Russell, Hilbert and Bernays, Hilbert and Ackermann, Chang and Keisler, and others. Note that the individual Hilbert is a member of two of these groups. Yet they remain two groups. Since we can count and group multitudes, we should recognize not only multitudes of individuals, as Leśniewski did, but also multitudes of multitudes, of second and higher order, as well as multitudes of mixed order. The resulting hierarchy of multitudes resembles the cumulative hierarchy of set theory but differs from it in two crucial respects, both of which would gain Leśniewski’s approval. There is no empty multitude, and there is no difference between a singleton multitude and its sole member. Where we part company from Leśniewski is in affirming that a plurality can be member of a higher-order plurality.

Acceptance of this entails a radical expansion of logic. All the details of how this should go are not yet clear, for example it is not clear whether there is a universal multitude, as there is a universal set in Quine's New Foundations system, or rather an open Zermelotype hierarchy, or finally an NBG-style distinction between "ordinary" multitudes and multitudes too "large" to be members of others. ${ }^{11}$ However, whichever of these may turn out tobe correct, if we grant higher-order multitudes, then we reinforce the nominalist's hand. Firstly, the only items required to generate multitudes of all the orders are individuals or urelements. More particularly, we need at least two individuals before a hierarchy is generated. Secondly, the multitudes all come for free on the back of the urelements: it is inconsistent to accept several things and deny their multitude (contrast set theory again). So the ontology is nominalistically acceptable: the multitudes are particulars and inherit their location from their members, but the world does not get any more crowded, since each multitude comprises its several members. Entities are multiplied, but of necessity. Finally, assuming, as is plausible, that an axiom of infinity governs the cumulation of multitudes, then as few as two individuals generate infinitely many multitudes and an infinite multitude. This has advantages when it comes to considering the ontological status of arithmetic.

11 For thoughts on the basic logic and the alternatives, see Simons 2012 and Simons forthcoming. 
Assume we are given a domain $D$ of individuals. On our new understanding, $D$ is not a set, but simply the multitude of these individuals. In the salient case, $D$ is the maximal first-order multitude $\mathrm{U}$, whose members are all individuals. We let letters $a, b, c$, etc. stand for arbitrary individuals, which are members of $D$. Multitudes have their members essentially and their identity conditions are extensional. But they have no order or repetition so cannot as they stand represent sequences. But suppose we have several things, say $a, b, c$ and $d$. We can represent the sequence $<c, a, d, b>$ which has no repetitions by a multitude of multitudes whose members nest by inclusion thus: $c$ ca $c a d c a d b$. Sequences with repetitions can be represented by adding to a sequence without repetitions, and whose members' first occurrences are correctly situated, further pairs indicating the substitution of a repeated member occurring earlier in the sequence for the member at the right place in the non-repeating sequence, so e.g. $<c, a, a, c>$ is represented by $c$ ca $c a d c a d b d a b c$. The "dummy" members can be selected arbitrarily from among other things not numbered among the members to be repeated. We can then collect these multitudes representing sequences of a given length into a further higherorder multitude and this is then fit to be the extension of a predicate, in this case one with four places.

Infinite sequences can be represented in the same way, using infinite nested multitudes and replacement pairs. Since the arity of relations has no upper limit, the length of sequences can on finite domains outrun the number of individuals in the domain. In that case multitudes from higher in the hierarchy can if necessary be co-opted to serve as dummies in long sequences.

On this basis we are able to represent the extensions of relations and functions. In particular if we are given a multitude of expressions $E$ constituting a language, we have the resources to construct an ersatz for an interpretation function from $E$ to multitudes over $D$. How we do this, in particular if the members of $E$ are themselves all particulars (the road Tarski avoided) is something over which I shall wave a hand here, simply stating that it can be done. The procedure bears a non-accidental resemblance to the use of set theory in standard platonistic semantics.

The procedure is a little more complicated for a Leśniewskian language with empty and plural names at the lowest level. Empty names, as in free logic, are simply not assigned a denotatum, while a plural name is assigned the multitude of individuals it designates. Sequences then have to start from higher-order multitudes, but they are available. Empty 
names and predicates which can take empty names give a little more trouble. One trick would be to concoct something to act as a null individual and arrange everything around that. A more realistic and philosophically satisfying if mathematically messier solution is to give explicit interpretation clauses for expressions containing empty names or quantifying positions into which empty names can slot. In this way there is the prospect of providing a formal semantic framework for Leśniewski’s logic. In any case, unexemplified predicates require special clauses if one is not to have recourse to a null item. As ever, the platonist solution spares tedious but honest toil.

\section{Consequences for Nominalists}

I claim that the employment of higher-order multitudes enables a nominalist to give a semantic treatment of first- and higher-order logics in a way which defuses the claims of Church, ${ }^{12}$ Quine ${ }^{13}$ and others that higher-order logic must be platonistically interpreted. It continues the work begun by George Boolos in rescuing higher-order logic from the strictures of Quine. ${ }^{14}$ Boolos passed too lightly over the need to provide extensions for predicates, assuming something like the standard tricks would work. They do, but only once we ascend to higher orders of multitude.

Two obvious worries arise. One is that the treatment is not really nominalistic. I concede that it will not please every kind of nominalist. In particular, one of Goodmanian persuasion who considers that there can be "no distinction of entities without a distinction of content" ${ }^{15}$ will not accept higher-order multitudes, since the higher-order multitude $a b b c$ is no different in content (meaning here: individuals on which it is ultimately based) from the different higher-order multitude $a c a b$ or indeed from the first-order multitude $a b c$. I agree that this is Goodman's view, and it is quite likely that Leśniewski would have sympathized. I simply disagree and part company from them. The other worry is about how realistic this all is. The concocting of entities fit to be extensions etc. seems gamelike, arbitrary, and very far from the intricacy of truth-making. Agreed again, but here is the difference. Models do not have to be realistic: they just have to have the right logical multiplicity. That is where the semantics within mathematics differs from the semantics of real things and real truths.

12 Church 1951.

13 Quine 1970, Ch. 5.

14 Boolos 1998, Chs. 3-5.

15 Goodman 1972, $159 f$. 
Let us suppose then that a nominalist can live with her conscience in employing the notions of interpretation, model, logical truth and logical consequence. What does this avail her? Here is a suggestion for some payout. Take Whitehead's and Russell's account of the logical status of the truths of Peano arithmetic in Principia Mathematica. In order to have enough objects around for all the natural numbers to be correctly exemplified at Type 2 (taking individuals as Type 0 ), they had to postulate the existence of infinitely many individuals. This undercut logicism at a stroke, since the assumption cannot be reckoned to be a logical or necessary truth. Set theoretical foundations for arithmetic get round the problem because of the unconditional existence of the empty set, the distinctness of singletons from their members, and the existence of an infinite set starting from the empty set as sole urelement. In our case we don't have an empty multitude to start the ball rolling, and singletons collapse to their sole members. Infinitely many objects cannot be unconditionally guaranteed but only in a universe with at least two individuals. If it is logically necessary that there are at least two individuals (Frege thought it was: he had the True and the False) then logicism is correct. But if there logically could be fewer than two individuals then logicism is not correct. What is correct is the if there are at least two individuals then Peano arithmetic follows. Since there are as a matter of fact many more than two individuals, possibly indeed infinitely many, there is no fear of Peano arithmetic being actually false, as there was with Principia. Logicism is false, but not by as wide a margin as we thought.

Other mathematical theories will make stronger demands than simple arithmetic, and that suggests an if-thenist approach to them all. Given certain assumptions, for example about the cardinality of the domain, what follows? We know since Gödel that logicomathematical truth outruns proof, so the consequence involved must be, as Tarski took it to be, a semantic, not a proof-theoretic notion. Nominalists need no longer worry that availing of this notion involves them in back-door platonism via semantics. This means that a formalist account of pure mathematics regains its attractiveness. Such an account has been proposed recently by Alan Weir, ${ }^{16}$ though Weir still ties mathematical truth to proof, which is surely wrong post-1931. Nevertheless I now think that Hilbert was right, as is Weir, that pure mathematics is about what propositions follows from what assumptions, and is not the descriptive geography of an independently existing ideal realm. The theorems in mathematics texts are (in general) not unconditionally true, indeed some, taken categorically, will be false.

8 Open Questions and Conclusion

16 Weir 2010. 
There are many areas concerned with truth that have not been mentioned here. Some are left unclarified by truth-maker theory, others untouched by multitude theory. The correct formulation of the logic concerning higher-order multitudes needs work. Work on makers for vague propositions and a suitable multivalent logic is in hand but incomplete. ${ }^{17} \mathrm{I}$ have not touched on matters of logical modality or analyticity. ${ }^{18}$ The truth-making account of true applied probability propositions is unclear. And as indicated earlier I have not addressed matters of value.

However it seems to me that there is here a fairly robust link between truth-making considerations applicable in the real world and matters associated with logical consequence. The Entailment Principle of truth-making states that if $M$ makes it true that $p$ and $q$ follows logically from $p$ then $M$ makes it true that $q$. That brings both together. Being a hairshirt nominalist is not an easy intellectual pathway, but if with multitudes there is no need for abstract entities in semantics, such a nominalist can sleep a little more comfortably at night, and perhaps Tarski can rest more easily in his grave.

\section{References}

Armstrong, D. M. 2004. Truth and Truthmakers. Cambridge: Cambridge University Press. Bigelow, J. 1988. The Reality of Numbers: A Physicalist's Philosophy of Mathematics. Oxford: Clarendon Press.

Boolos, G. 1998. Logic, Logic, and Logic. Cambridge, Mass.: Harvard University Press. Church, A. 1951. The Need for Abstract Entities in Semantic Analysis. American Academy of Arts and Sciences Proceedings 80, 100-113.

Feferman, A. B. and Feferman, S. 2004. Alfred Tarski: Life and Logic. Cambridge: Cambridge University Press.

Goodman, N. 1972, A World of Individuals, in his Problems and Projects. Indianapolis and New York: Bobbs-Merrill, 155-72.

Hodges, W. 1997. A Shorter Model Theory. Cambridge: Cambridge University Press. Mulligan, K., Simons, P. M. and Smith, B. 1984. Truth-Makers. Philosophy and Phenomenological Research 44, 287-322.

Quine, W. V. 1970. Philosophy of Logic. Cambridge, Mass.: Harvard University Press.

17 Simons 2010.

18 For some thoughts on the latter, see Simons 2007. 
Simons, P. M. 1983. Class, Mass and Mereology. History and Philosophy of Logic 4, 157-80.

_ 2007. Truth in Virtue of Meaning. In J.-M. Monnoyer, ed., Metaphysics and Truthmakers. Frankfurt/Main: Ontos, 67-78.

— 2008. Truth on a Tight Budget: Tarski and Nominalism. In D. Patterson, ed., New Essays on Tarski and Philosophy. Oxford: Clarendon Press, 369-89.

- 2010. Supernumeration: Vagueness and Numbers. In R. Dietz and S. Moruzzi, eds., Cuts \& Clouds. Vaguness, Its Nature, and Its Logic. Oxford: Clarendon Press, 482-490.

— 2012. On Multitudes. http://www.glli.uni.opole.pl/index en.php?id=publications

_forthcoming. The Ontology and Logic of Higher-Order Multitudes. In M. Carrara, F. Moltmann and A. Arapinis, eds., Plurality and Unity. New Essays in Logic and Semantics. Oxford: Clarendon.

Tarski, A. 1933. Pojeccie prawdy w jezykach nauk dedukcynych. Prace Towarzystwa Naukowego Warszawskiego. Wydział III: Nauk Matematzcyno-Fizzycznych nr. 34. Warsaw: PWN. Reprinted in Tarski 1995, 13-172. Translation: The Concept of Truth in Formalized Languages, in Tarski 1983, 152-278.

— 1936. O pojęciu wynikania logicznego. Przegląd Filozoficzny 39, 58-68. Reprinted in Tarski 1995, 186-202. Translation: On the Concept of Logical Consequence, in Tarski 1983, 409-420.

— 1983. Logic, Semantics, Metamathematics. Papers from 1923 to 1938. 2nd ed., Indianapolis: Hackett.

— 1995. Pisma Logiczno-Filozoficzne, Tom 1. Prawda. Warsaw: Wydawnictwo Naukowe PWN.

Weir, A. 2010. Truth through Proof. A Formalist Foundation for Mathematics. Oxford: Clarendon Press. 